ORIGINAL ARTICLE

\title{
Hepato curative effects of Silymarin and Cymbopogoncitratus stem infusion: RCT
}

\author{
SIDRA MUMAL ${ }^{1}$, ABDUL AZEEM ${ }^{2}$, TALAL ZAFAR $^{3}$, HINA ASLAM $^{4}$, TASNEEM MURAD ${ }^{1}$, AAMNA KHOKHAR $^{4}$, TALHA \\ LAIQUE5* \\ ${ }^{1}$ Department of Pharmacology, Islamic international medical college, Rawalpindi -Pakistan \\ ${ }^{2}$ Department of Pharmacology, Watim Medical and Dental College, Rawalpindi -Pakistan \\ ${ }^{3}$ Department of Paediatrics, Hazrat Bari Imam Sarkar Medical and Dental College Islamabad -Pakistan \\ ${ }^{4}$ Department of Pharmacology, Islamabad Medical and dental College, Islamabad-Pakistan \\ ${ }^{5}$ Department of Pharmacology, Allama Iqbal Medical College, Lahore-Pakistan \\ ${ }^{*}$ Correspondence to: Dr. Talha Laique, Email: talhalaique51@gmail.com, Tel:+92-331-0346682
}

\begin{abstract}
People all around the world suffer from liver diseases, which is a serious health problem.

Purpose: To observe the synergistic effects of Silymarin and Cymbopogoncitratus stem infusion on liver in acetaminophen induced hepatotoxicity in rats.

Study Design: Laboratory-Based Randomized Control Trial.

Methodology: Total forty adult rats were divided into four groups (10 each). Group 1 was taken as control group. After initial sampling at day 0 , Acetaminophen $(300 \mathrm{mg} / \mathrm{kg})$ was injected to 30 rats via intra-peritoneal route. At day 8 , rats were further divided into three groups. Group 2 was a disease control group. Group 3 was given Silymarin $(100 \mathrm{mg} / \mathrm{kg})$ and group 4 was treated with Silymarin $(100 \mathrm{mg} / \mathrm{kg}$ ) plus Cymbopogoncitratus stem infusion $(130 \mathrm{mg} / \mathrm{kg})$ through gavage method for fourteen days. At day 21, rats were sacrificed for histological examination after terminal sampling.

Statistical Analysis: Mean \pm SEM was calculated and analyzed through SPSS 20. P-value less than 0.05 was considered statistically significant.

Results: Rats from group 2 showed marked elevation $(\mathrm{p}<0.05)$ in serum markers. There was marked sinusoidal dilatation and necrosis present in group 2 rats.Silymarinin group 3 and Silymarin plus Cymbopogoncitratus stem infusion in group 4 significantly lowered the biochemical enzymes as well as considerably reversed the histological changes in comparison to group 2 rats.

Conclusion: We concluded in present study that synergism was observed in group 4 rats. There was more reversal of hepatic injury in group 4 rats.

Key words: Cymbopogoncitratus, Silymarin and Synergism.
\end{abstract}

\section{INTRODUCTION}

People suffer from liver diseases globally, which is a serious health problem. ${ }^{1}$ Hepatic disorders has incidence around 20,000 people per year as documente. ${ }^{2}$ Liver pathology if left untreated, can lead to fibrosis, cirrhosis, and ultimately hepatic carcinoma. ${ }^{3,4}$ All these diseases add burden to the community due to inefficient long-term therapies ultimately causing death. ${ }^{4}$ Conventional medications like steroids, vaccinations, interferons and antiviral drugs showed various adverse side effects given for chronic illnesses as documented. ${ }^{5,6}$ As a result, plants and their hepato-protective potential attracted attention of various researchers recently as natural medicine and healthy eating habits are related with general population. ${ }^{1}$

Flavonoids are thought to be strong antioxidants because of their phenolic structures and ability to inhibit free radical-mediated activities. ${ }^{7} \quad$ "Silymarin," a flavonolignane derived from milk thistle, has been used to treat a variety of liver illnesses characterized by functional impairment or progressive necrosis. It's recognized for its antioxidant, anti-inflammatory, and anti-fibrotic properties, as well as its capacity to protect the liver against a range of diseases. By stabilizing the membrane, it works as a free radical scavenger, preventing lipid peroxidation and the resulting cell harm. ${ }^{8}$

Lemongrass tea, or Cymbopogoncitratus tea, is another delightful beverage. ${ }^{3,9}$ Infusions and decoctions prepared from C.citratus are commonly used in a number of nations by pouring boiling water over fresh or dried leaves. Epidemiological and experimental investigations have suggested that $C$.citratus has a hepatoprotective effect due to its antioxidant content and ability to scavenge free radicals. ${ }^{10,11}$ C.citratusstabilizes hepatocyte membranes, thus controlling cellular permeability and prevents serum aminotransferase and LDH leakage. This activity is attributed to the flavonoids found in it. Tannins present in it have anti-inflammatory as well as antioxidant effects.Citral, CGAs and caffeic acid boost the liver's mending and regenerating abilities.All of these mechanisms aid in the improvement of liver function and the reduction of blood enzymes that are commonly elevated in liver diseases. ${ }^{11-15}$

When herbs are utilized together, their efficacy is increased. According to certain experts, synergism and buffering laws are applied to the combination chemicals. ${ }^{16}$ In light of above description, we planned current project to evaluate hepato-protective effect of $C$. citratus stem infusions in a specific dose as an adjuvant medication therapy with Silymarin.

Objective: To observe the synergistic effects of Silymarin and Cymbopogoncitratus stem infusion on liver in acetaminophen induced hepatotoxicity in rats.

Methodology: This randomized-control trial was conducted from October 2018-19 using the balloting method at the Pharmacology department at IIMCT in partnership with the Multidisciplinary Research Lab and the Animal House at 
the National Institute of Health, Islamabad. Before beginning the study, the institute's accredited Ethical Review Committee authorized the research proposal. C.citratusstems were purchased at $\mathrm{Al}-\mathrm{Fatah}$ super store in Islamabad's Centaurus mall and forwarded to the National Agriculture Research Centre's (NARC) herbarium for identification and validation using taxonomic standards. These were grounded into powder with a blender and kept in air tight jar. Female rats and abnormal liver function tests were exclusion criteria. Rats were housed in a temperature-controlled facility with a 12 hour dark/light cycle and a constant temperature of 20-25 degrees Celsius. During the entire experiment, no mortality or morbidity was detected.

The rats were divided into four groups, each with ten rats. Intracardiac blood sampling was used to collect blood samples from two rats from each group on day 0 . Group 1 (control group) fed a regular diet and drank tap water. The rats in the other three groups received a single intraperitoneal dose of Acetaminophen $300 \mathrm{mg} / \mathrm{kg}^{17}$ on day 0 to induce hepato-toxicity. On the eighth day, a second blood sample was taken from two rats from each of the three groups to examine the study's progress. After confirmation, group-2 (disease control) rats received no therapy further. Group-3 rats were given Silymarin $100 \mathrm{mg} / \mathrm{kg}^{18}$ by intragastric gavage once a day, while group-4 rats were given Silymarin plus C.citratus stem infusion once a day in the morning by gavage method. Preparation of C.citratus stem infusion involved that, the powder was steeped in boiling water $\left(100{ }^{\circ} \mathrm{C}\right)$ for $130 \mathrm{mg} / \mathrm{kg}$, and the infusion was allowed to sit for 10 minutes before being filtered. ${ }^{19}$ After 21-day experiment, terminal blood sampling was done via cardiac puncture with a $3 \mathrm{cc}$ syringe after anesthesia with chloroform.Blood samples were centrifuged at 3500 RPM for 5 minutes $^{20}$ after clot formation using a Bench top centrifuge. The serum was separated in tubes for final biochemical analysis, which was performed on same day using ALT and AST kits from Merck on a Chemistry analyzer. Rats were sacrificed and liver was preserved in $10 \%$ formaldehyde for histopathological examination.

Statistical Analysis: Parameters to assess liver injury were sinusoidal dilatation and congestion with necrosis. Observation of slides was done under 10X, 40X objectives to observe the changes. Respective data was analyzed in SPSS version 20. Mean and standard errors were calculated for the quantitative variables. Categorial or qualitative variables were demonstrated by percentage. The Post hoc tuckeys test was applied for multiple comparison of these groups.

\section{RESULTS}

As rats in group 2 (disease control) were given Acetaminophen, their transaminase levels increased considerably $(p<0.05)$ when compared to rats in group1 (normal control).When compared to group 3 rats who were treated with Silymarin, the results in group 4 (silymarin+ C.citratus stem infusion) showed a significant reduction in serum biomarkers (table-1).

\begin{tabular}{|l|l|l|l|}
\hline \multicolumn{4}{|c|}{ Table-1: Mean \pm SEM Of ALT And AST Values among All Groups } \\
\hline Groups $n=10$ & "ALT" & "AST" & P-value \\
\hline Group 1 & $36.40 \pm 3.655$ & $40.20 \pm 3.397$ & \\
\hline
\end{tabular}

\begin{tabular}{|l|l|l|l|}
\hline Group 2 & $157.60 \pm 7.827$ & $129.00 \pm 8.637$ & \multirow{2}{*}{$<0.05^{\star}$} \\
\cline { 1 - 3 } Group 3 & $91.00 \pm 1.517$ & $75.80 \pm 2.709$ & \\
\hline Group 4 & $61.20 \pm 3.891$ & $62.60 \pm 2.421$ & \\
\hline
\end{tabular}

${ }^{*}$ Statistically Significant; ALT = Alanine aminotransferase; $A S T=$ Aspartate aminotransferase

Table-2 depicted comparison between different groups with respect to ALT AND AST serum levels respectively.

\begin{tabular}{|l|l|l|}
\hline \multicolumn{3}{|l|}{$\begin{array}{l}\text { Table-2: Post Hoc Comparison of "ALT" and “AST" B/W Groups } \\
(\mathrm{n}=40)\end{array}$} \\
\hline Comparison Of Groups & $\begin{array}{l}\text { ALT "Mean } \\
\text { difference" }\end{array}$ & $\begin{array}{l}\text { AST "Mean } \\
\text { difference" }\end{array}$ \\
\hline Group 1 vs. group 2 & $-121.200^{*}$ & $-88.800^{*}$ \\
\hline Group 1 vs. group 3 & $-54.600^{*}$ & $35.600^{*}$ \\
\hline Group 1 vs. group 4 & $-24.800^{*}$ & $-22.400^{*}$ \\
\hline Group 2 vs. group 3 & $66.600^{*}$ & $53.200^{*}$ \\
\hline Group 2 vs. group 4 & $96.400^{*}$ & $66.400^{*}$ \\
\hline Group 3 vs. group 4 & $29.800^{*}$ & $13.200^{*}$ \\
\hline
\end{tabular}

${ }^{*}$ Statistically Significant

All groups in present study showed sinusoidal dilation in terms of mean \pm SEM as shown in table-3.

\begin{tabular}{|c|c|c|}
\hline Groups $n=10$ & Sinusoidal dilatation & P-value \\
\hline Group 1 & $9.66 \pm 0.821$ & \multirow{4}{*}{$<0.05^{*}$} \\
\hline Group 2 & $55.50 \pm 2.654$ & \\
\hline Group 3 & $24.40 \pm 0.980$ & \\
\hline Group 4 & $27.90 \pm 1.057$ & \\
\hline
\end{tabular}

${ }^{*}$ Statistically Significant

Histological presentation of sinusoidal dilation in all four groups was shown in figure-1.

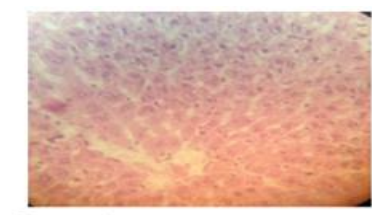

Group 1

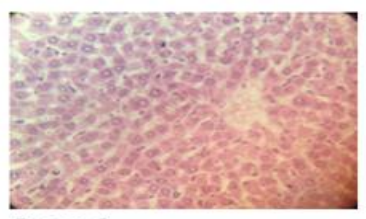

Group 3

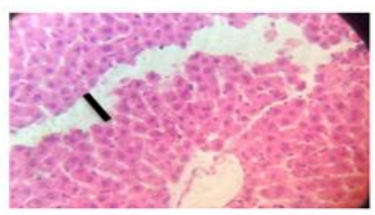

Group 2

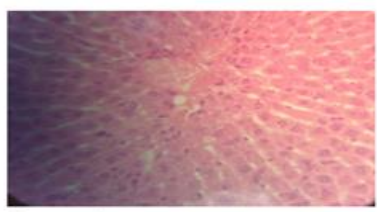

Group 4
Figure-1: Sinusoidal diameter of hepatic lobule among groups.

Congestion and necrosis was present in all rats of group 2 , $80 \%$ in group 3 and $60 \%$ in group 4 as shown in table- 4 .

\begin{tabular}{|l|l|l|l|}
\hline \multicolumn{3}{|c|}{ Table-4: Congestion and Necrosis Among All Groups } \\
\hline \multirow{2}{*}{ GROUPS } & CONGESTION & \multirow{2}{*}{ TOTAL } \\
\cline { 2 - 3 } & Absent $(\%)$ & $\begin{array}{l}\text { Present } \\
(\%)\end{array}$ & \\
\hline Group 1 & $10(100 \%)$ & $0(0 \%)$ & 10 \\
\hline Group 2 & $0(0 \%)$ & $10(100 \%)$ & 10 \\
\hline Group 3 & $2(20 \%)$ & $8(80 \%)$ & 10 \\
\hline Group 4 & $4(40 \%)$ & $6(60 \%)$ & 10 \\
\hline
\end{tabular}

Histological presentation of congestion and necrosis in all four groups was shown in figure-2 by using $\mathrm{H} \& \mathrm{E}$ stain. 

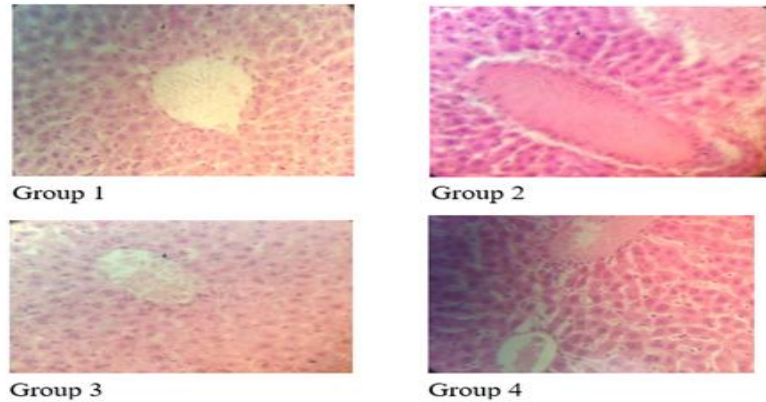

Group 3

Group 4

Figure-2:Sections of liver illustrating congestion and necrosis among groups.

\section{DISCUSSION}

Transaminases, such as ALT and AST, are crucial for diagnosing, confirming, and evaluating the extent of liver injury in clinical and experimental settings because their levels are elevated in hepatic ailments.In this study, rats in experimental groups (groups 2-4) were given a single intraperitoneal injection of $300 \mathrm{mg} / \mathrm{kg}$ acetaminophen to cause acute liver injury, which resulted in a substantial increase in serum ALT and AST levels when compared to the normal control group 1.The disease control group was subsequently assigned to group 2 .

Jersiah and colleagues employed a $300 \mathrm{mg} / \mathrm{kg}$ dose of Acetaminophen intraperitoneal injection in rats to elicit acute hepatotoxicity and elevated "ALT" and "AST" levels in rats, which supports this study. ${ }^{21}$ Both Silymarin and C.citratus are produced from plants and have hepatoprotective properties due to their antioxidant capacity. C.citratushas received special attention in this study because it is a commonly consumed beverage by individuals.

A comparison was made with Silymarin, a typical medicine that isn't new for liver sufferers, but its use is limited by its poor taste and low absorption.The use of Silymarin $100 \mathrm{mg} / \mathrm{kg}$ in group 3 reversed hepatic damage in the rats, according to the findings. The reversal is due to its membrane stabilizing function, which keeps intracellular enzymes from leaking out. The hepatoprotective activities of ethanol seed extract of Citrus paradisiMacfad (Grape Fruit) against paracetamol-induced hepatotoxicity in wistar rats were examined by Godswill J.Udom ${ }^{22}$ which support this study. The protective benefits of Silymarin against acetaminophen-induced hepatotoxicity and nephrotoxicity in mice, as studied by Bektur and colleagues, are similarly in agreement with our results of ALT and AST in group 3. ${ }^{7}$

Several studies have shown that Silymarin has a synergistic effect when used with other compounds. The combination of silymarin and ascorbic acid, one of the components of $C$. citratus plant, was evaluated by Mahrous A Ibrahim. His work disclosed that when they both were combined, maximum improvement of LFTs, histopathological changes were achieved. This is in accordance with our results in group 4 (Silymarin plus C.citratus stem infusion) when compared to group $2 .{ }^{23}$

Nouf Al- Rasheed investigated the interaction of Silymarin with chlorogenic acid and melatonin, both of which are important components of $C$. citratus. His work showed that there existed a synergistic effect between
Silymarin, Chlorogenic acids and Melatonin which decreased the serum levels of AST and ALT markedly and also attenuated oxidative DNA damage, apoptosis and fibrosis. This is also in support of our obtained results of group $4 .^{24}$

There was also a significant difference in results between groups 3 and 4 , indicating that while both treatments employed to reverse APAP-induced hepatotoxicity improved biochemical parameters, the combination of Silymarin and C. citratusstem infusionoutperformed Silymarin alone in terms of improving LFTs.

Limitation: Our study had several limitations like financial constraints, time restrictions small sample number and fewer resources.

\section{CONCLUSION}

We concluded that in Acetaminophen-induced hepatotoxicity in rats, combined drugs synergize each other's effect and have more favorable hepato-protective effects than alone Silymarin. So the chronic liver patients can enjoy the Lemon grass tea not only for recreational purpose but also as an adjuvant drug along with Silymarin to heal their liver.

Author's Contribution: SM \& AA: Overall supervision, write up and literature review. TZ \& HA: Statistics application analysis literature review, help in write up. TM, AK and TL: Literature review help in write-up.

Acknowledgement: I am thankful to Allah and all my colleagues for their help.

Conflict of Interest: None to declare

Financial Disclosure: None

\section{REFERENCES}

1. Xiong F, Guan YS. Cautiously using natural medicine to treat liver problems. World J Gastroenterol. 2017;23(19):3388-95.

2. Ganaie MA, Khan TH, Siddiqui NA, Ansari MN. Ameliorative effect of methanol extract of Rumex vesicarius on $\mathrm{CCl} 4$ induced liver damage in Wistar albino rats. Pharm Biol. 2015;53(8):1163-7.

3. Ali Saber Sarg N. The Role of Cymbopogon Citratus Extract in Protecting the Liver Against Injurious Effect of Dimethylnitrosamine in Rats. Int $\mathrm{J}$ Clin Dev Anat. 2015;1(4):89.

4. Furtado KS, Prado MG, Aguiar e Silva MA, Dias MC, Rivelli DP, Rodrigues MAM, et al. Coffee and Caffeine Protect against Liver Injury Induced by Thioacetamide in Male Wistar Rats. Basic Clin Pharmacol Toxicol. 2012;111(5):339-47.

5. Koh PH, Mokhtar RAM, labal M. Antioxidant potential of Cymbopogon citratus extract: Alleviation of carbon tetrachloride-induced hepatic oxidative stress and toxicity. Hum Exp Toxicol. 2012;31(1):81-91.

6. Freitag AF, Cardia GFE, da Rocha BA, Aguiar RP, SilvaComar FM de S, Spironello RA, et al. Hepatoprotective Effect of Silymarin ( Silybum marianum ) on Hepatotoxicity Induced by Acetaminophen in Spontaneously Hypertensive Rats. Evidence-Based Complement Altern Med. 2015;2015:1-8.

7. Bektur NE, Sahin E, Baycu C, Unver G. Protective effects of silymarin against acetaminophen-induced hepatotoxicity and nephrotoxicity in mice. Toxicol Ind Health. 2013;32(4):589600.

8. Jalali SM, Najafzadeh $\mathrm{H}$, Bahmei $\mathrm{S}$. Protective role of silymarin and D-penicillamine against lead-induced liver 
toxicity and oxidative stress. Toxicol Ind Health. 2017;33(6):512-8.

9. Somparn N, Saenthaweeuk S, Naowaboot J, Thaeomor A, Kukongviriyapan V. Effect of lemongrass water extract supplementation on atherogenic index and antioxidant status in rats. Acta Pharm. 2018;68(2):185-97.

10. Koh PH, Mokhtar RAM, Iqbal M. Antioxidant potential of Cymbopogon citratus extract: Alleviation of carbon tetrachloride-induced hepatic oxidative stress and toxicity. Hum Exp Toxicol. 2012;31(1):81-91.

11. Ekpenyong CE, Akpan EE, Daniel NE. Phytochemical Constituents, Therapeutic Applications and Toxicological Profile of Cymbopogon citratus Stapf ( DC ) Leaf Extract . J Pharmacogn Phytochem. 2014;3(1):133-41.

12. Ekpenyong CE, Akpan E, Nyoh A. Ethnopharmacology, phytochemistry, and biological activities of Cymbopogon citratus (DC.) Stapf extracts. Chin J Nat Med. 2015;13(5):321-37.

13. Manvitha K, Bidya B. Review on pharmacological activity of Cymbopogon citratus. Int J Herb Med. 2014;1(6):5-7.

14. Nambiar V, Matela $\mathrm{H}$. Potential functions of Lemon grass (Cymbopogon citratus) in health and disease. Int $\mathrm{J}$ Pharm Biol Arch. 2012;3(5):1035-43.

15. Garcia R, Ferreira JP, Costa G, Santos T, Branco F, Caramona $\mathrm{M}$, et al. Evaluation of anti-inflammatory and analgesic activities of Cymbopogon citratus in vivopolyphenols contribution. Res J Med Plant. 2015;9(1):1-13.

16. Aleksandrova $\mathrm{K}$, Bamia $\mathrm{C}$, Drogan D, Lagiou $\mathrm{P}$, Trichopoulou A, Jenab M, et al. The association of coffee intake with liver cancer risk is mediated by biomarkers of inflammation and hepatocellular injury: Data from the European Prospective Investigation into Cancer and Nutrition. Am J Clin Nutr. 2015;102(6):1498-508.

17. Wang JX, Zhang C, Fu L, Zhang DG, Wang BW, Zhang ZH, et al. Protective effect of rosiglitazone against acetaminophen-induced acute liver injury is associated with down-regulation of hepatic NADPH oxidases. Toxicol Lett. 2017;265:38-46.

18. Das S. Hepatoprotective activity of methanol extract of Fenugreek seeds on rats. Int J Pharm Sci Res. 2014;5(4):1506-13.

19. Hanisa H, Hadijah H, Rasedee A, Tarmizi AS. Sub-acute oral administration of Cymbopogon citratus stem infusion and its effects on blood biochemical parameters, body and organ weights in rats. 2011;39(1):1-7.

20. Ebrahimi E, Shirali S, Talaei R. The Protective Effect of Marigold Hydroalcoholic Extract in STZ-Induced Diabetic Rats: Evaluation of Cardiac and Pancreatic Biomarkers in the Serum. J Bot. 2016;2016:1-6.

21. Jarsiah $P$, Nosrati $A$, Alizadeh $A$, Hashemi-Soteh SMB. Hepatotoxicity and ALT/AST Enzymes Activities Change in Therapeutic and Toxic Doses Consumption of Acetaminophen in Rats. Int Biol Biomed J [Internet]. 2017 [cited 2019 Oct 5];3(3):119-24. Available from: http://ibbj.org/article-1-129-en.html

22. Udom GJ, Yemitan OK, Umoh EE, Mbagwu HOC, Ukpe E, Thomas PS. Journal of Herbal Drug. 2018;8(4):219-25.

23. Ibrahim M, Abdel-Karim R, Tamam H, Mohamed A, Wani F. Protective effect of silymarin and ascorbic acid in valproic acid-induced hepatic toxicity in male albino Rats. Mansoura J Forensic Med Clin Toxicol. 2017;25(2):33-49.

24. Al-Rasheed N, Faddah L, Al-Rasheed N, Bassiouni YA, Hasan IH, Mahmoud AM, et al. Protective effects of silymarin, alone or in combination with chlorogenic acid and/or melatonin, against carbon tetrachloride-induced hepatotoxicity. Pharmacogn Mag. 2016;12(46):S337-45. 